\title{
NFE2L2 is associated with NQ01 expression and low stage of hepatic fibrosis in patients with chronic hepatitis C
}

\author{
Kamila Małgorzata Wójcik1,A-F, Anna Piekarska ${ }^{1, E, F}$, Bożena Szymańska ${ }^{2, C}$, Elżbieta Jabłonowska ${ }^{2, A-F}$ \\ ${ }^{1}$ Department of Infectious Diseases and Hepatology, Medical University of Lodz, Poland \\ 2 Central Laboratory, Medical University of Lodz, Poland \\ A - research concept and design; B - collection and/or assembly of data; C - data analysis and interpretation; \\ $D$ - writing the article; $E$ - critical revision of the article; $F$ - final approval of the article
}

\section{Address for correspondence}

Kamila Wójcik

E-mail: camilaw@tlen.pl

Funding sources

None declared

Conflict of interest

None declared

Received on January 15, 2019

Reviewed on February 14, 2019

Accepted on March 20, 2019

Published online on March 28, 2019

\section{Abstract}

Background. Oxidative stress is extremely important in the pathogenesis of chronic hepatitis C virus (HCV). In response to oxidative stress, adaptive antioxidant defenses are upregulated in the liver. The balance between antioxidant response and oxidative stress plays a key role in hepatic injury in $\mathrm{HCV}$ infection.

Objectives. The objective of this study was to assess the hepatic expression of the antioxidant genes GFER (growth factor erv1-like) and NQO1 (NAD(P)H:quinone oxidoreductase-1) and the regulatory gene NFE2L2 (nuclear factor erythroid 2-related factor-2) in liver biopsy specimens obtained from chronic HCV patients with regard to selected clinical parameters and histology, and to determine whether GFER and NQO1 expression is dependent on NFE2L2.

Material and methods. The study group consisted of 42 patients with chronic HCV. Reverse transcription polymerase chain reaction (RT-PCR) was used to analyze the expression of antioxidant and regulatory genes in liver biopsy samples.

Results. Positive correlation was observed between the hepatic expression of NFE2L2 and NQ01 in the chronic HCV patients $(p<0.0001)$. The hepatic expression of NFE2L2 was significantly lower in patients with advanced liver fibrosis $(p=0.05)$. However, there was no significant difference in the hepatic expression of GFER and NQ01 in relation to the progression of liver steatosis, inflammation and fibrosis.

Conclusions. The hepatic expression of NFEZL2 is associated with NQO1 and low stage of hepatic fibrosis in patients infected with HCV.

Key words: hepatitis C, liver fibrosis, antioxidant genes, regulatory gene

Cite as

Wójcik KM, Piekarska A, Szymańska B, Jabłonowska E. NFE2L2 is associated with $N Q 01$ expression and low stage of hepatic fibrosis in patients with chronic hepatitis C. Adv Clin Exp Med. 2019;28(9):1237-1241. doi:10.17219/acem/105852

DOI

10.17219/acem/105852

Copyright

Copyright by Author(s)

This is an article distributed under the terms of the

Creative Commons Attribution Non-Commercial License

(http://creativecommons.org/licenses/by-nc-nd/4.0/) 


\section{Introduction}

Despite increasing access to effective antiviral therapies, HCV infection remains an important epidemiological issue worldwide, with about 3 to 4 million cases reported each year. ${ }^{1}$ Approximately $75-85 \%$ of $\mathrm{HCV}$-infected patients develop chronic $\mathrm{HCV}$ infection, $20 \%$ of whom progress to cirrhosis. ${ }^{2}$

It is well known that oxidative stress plays a significant role in $\mathrm{HCV}$ pathogenesis. ${ }^{3,4}$ Hepatitis $\mathrm{C}$ virus core proteins induce the mitochondrial production of reactive oxygen species (ROS), leading to the peroxidation of membrane lipids. In response to this oxidative stress, adaptive antioxidant defenses such as antioxidant enzymes are upregulated in the liver. The main regulator of this self-protective antioxidant mechanism is nuclear factor erythroid 2-related factor-2 (Nrf2), encoded by the NFE2L2 gene, which activates the expression of antioxidant proteins such as glutathione perioxidase, $\mathrm{NAD}(\mathrm{P}) \mathrm{H}$-quinone oxidoreductase-1, superoxide dismutase, catalase, glutathione S-transferases, glutamate-cysteine ligase, heme oxygenase-1, thioredoxin reductase-1, and augmenter of liver regeneration. ${ }^{5} \mathrm{NQO} 1(\mathrm{NAD}(\mathrm{P}) \mathrm{H}$ :quinone oxidoreductase-1) is a cytosolic flavoprotein encoded by the gene NQO1 that inhibits oxidative stress by the detoxification of superoxide anions and the regeneration of reduced forms of protective endogenous antioxidant compounds. ${ }^{6}$

Augmenter of liver regeneration (ALR) is encoded by the growth factor erv1-like (GFER) gene and is responsible for liver regeneration through the upregulation of the mitogen-activated protein kinase pathway, as well as interleukin-6 (IL-6) and tumor necrosis factor- $\alpha{ }^{7}$

The aim of the present study is to assess the hepatic expression of the antioxidant genes GFER and NQO1 and the regulatory gene NFE2L2 in liver biopsy specimens obtained from patients with chronic $\mathrm{HCV}$ in relation to selected clinical parameters and histological factors, and to determine whether GFER and NQO1 expression is dependent on NFE2L2.

\section{Material and methods}

The study included 42 adult patients with chronic HCV. Inclusion criteria were as follows: 1 . The presence of positive serum anti-HCV antibodies and detectable HCV viremia lasting more than 6 months; 2 HCV genotype 1 . Exclusion criteria:

1. other systemic or inflammatory diseases;

2. other causes of liver disease;

3. cirrhosis (revealed by liver biopsy);

4. previous anti-HCV treatment;

5. treatment with other medications including antioxidant vitamin and diet supplements;

6. HIV/HBV confection;

7. pregnancy.
The study was approved by the ethical committee of the Faculty of Medicine, Medical University of Lodz, Poland, and informed written consent was obtained from every patient. Liver biopsies were performed as part of the routine standard of care for the subjects studied. The grade of inflammation and the state of fibrosis were determined according to the Batts and Ludwig scale. Steatosis was assessed with Bruntet and Kleiner's histological scoring. Hepatitis C virus RNA was measured using reverse transcription PCR (RT-PCR) with COBAS AMPLICOR HCV v. 2.0 (Roche Diagnostic Inc., Basel, Switzerland). Hepatitic $\mathrm{C}$ virus genotype was assessed using a hybridization method (InnoLipa HCV; Innogenetics, Ghent, Belgium).

\section{Statistical analysis and polymerase chain reaction}

\section{Total RNA isolation}

Total RNA was isolated using the $\operatorname{mirVana}^{\mathrm{TM}}$ miRNA isolation kit (Ambion ${ }^{\circledR}$ Thermo Fisher Scientific, Waltham, USA) according to the manufacturer's protocol.

\section{mRNA expression}

Homo sapiens-specific TaqManGene Expression Assay (Applied Biosystems Inc., Foster City, USA) for GFER, NQO1 and NFE2L2 mRNA was used for gene expression assays. cDNA generation was performed using $250 \mathrm{ng}$ of total RNA with High Capacity cDNA Reverse Transcription Kits according to the manufacturer's protocols (Applied Biosystems). Expression levels of mRNA were determined using beta-actin (ACTB) as an endogenous control.

\section{Real-time polymerase chain reaction analysis}

TaqMan PCR assays were determined using Sequence Detection System v. 2.0 software (Thermo Fisher Scientific). Fold induction values were measured according to $2 \Delta \Delta \mathrm{Ct}$, where $\Delta \mathrm{Ct}$ defines the differences in cycle threshold numbers between the target gene and endogenous control, and $\Delta \Delta \mathrm{Ct}$ defines the relative change in these differences between study and control groups.

\section{Statistical analysis}

The Mann-Whitney test was used to determine differences between the examined groups. Correlations between the hepatic expression of antioxidant genes GFER and NQO1 and the regulatory gene NFL2L2 were assessed with Spearman's rank correlation coefficient. Values of $\mathrm{p} \leq 0.05$ were considered to be statistically significant. 


\section{Results}

\section{Study group}

The study group consisted of 42 patients with chronic HCV infection: 11 women and 31 men. The median age of patients was 32 years (LQ 21 years-UQ 49 years). The median plasma HCV viral load was 4,145,000 IU/mL (LQ 388,000 IU/mL-UQ 6,890,000 IU/mL). The characteristics of the patients are presented in Table 1.

Table 1. Characteristics of the study group

\begin{tabular}{|l|c|c|c|}
\multirow{2}{*}{} & \multicolumn{3}{|c|}{ HCV infection $(\mathrm{n}=42)$} \\
\cline { 2 - 4 } & median & LQ-UQ & min-max \\
\hline Age [years] & 32 & $21-49$ & $18-67$ \\
\hline ALT U/L & 54 & $39-83$ & $23-336$ \\
\hline HCV-RNA IU/mL & $4,145,000$ & $388,000-$ & $118,000-$ \\
\hline GFER & 1.46 & $0.890,000$ & $118,000,000$ \\
\hline NQO1 & 1.46 & $0.98-1.69$ & $0.06-3.98$ \\
\hline NFE2L2 & 2.30 & $1.50-3.83$ & $0.21-12.33$ \\
\hline
\end{tabular}

LQ - lower quartile; UP - upper quartile; ALT - alanine aminotranferase.

\section{Hepatic expression of GFER, NQO1, NFE2L2, and HCV viral load}

The study group was divided into 2 subgroups: one with HCV-RNA > 600,000 IU/mL and the other with
HCV-RNA < 600,000 IU/mL. No significant difference in the hepatic expression of GFER, NQO1 and NFE2L2 was observed between the 2 groups (Table 2).

\section{Hepatic expression of GFER, NQO1 and NFE2L2 in the context of inflammation, steatosis and fibrosis}

Advanced fibrosis $(S \geq 2)$ was detected in 34 patients. No significant difference in the hepatic expression of GFER or NQO1 was observed in relation to the progression of liver fibrosis. However, the hepatic expression of NFE2L2 was significantly lower in patients with advanced liver fibrosis ( $\mathrm{p}=0.05$ ) (Table 3 ). No relationships were found between the hepatic expression of GFER, NQO1 or NFE2L2 and the grade of inflammatory activity (Table 4). Again, the hepatic expression of GFER, NQO1 or NFE2L2 was not associated with the presence of liver steatosis (Table 5). However, older age was reported in patients with the higher grade of liver inflammation $(\mathrm{p}<0.0001)$ and HCV-RNA > 600,000 IU/mL $(\mathrm{p}=0.03)$ (Tables 2,4).

\section{Correlations between hepatic expression of GFER, NQO1 and NFE2L2}

A significant positive correlation was found between the hepatic expression of NFE2L2 and NQO1 in chronic HCV patients $(\mathrm{p}<0.0001)$. However, the hepatic expression of NFE2L2 was not associated with GEFR (Table 6).

Table 2. Hepatic expression of GFER, NQO1 and NFE2L2 according to HCV viral load

\begin{tabular}{|c|c|c|c|c|c|c|c|}
\hline & \multicolumn{3}{|c|}{$\begin{array}{c}\text { HCV-RNA }<600,000 \mathrm{IU} / \mathrm{mL} \\
(n=15)\end{array}$} & \multicolumn{3}{|c|}{$\begin{array}{c}\text { HCV-RNA }>600,000 \mathrm{IU} / \mathrm{mL} \\
(n=27)\end{array}$} & \multirow{2}{*}{$p$-value } \\
\hline & median & $\min -\max$ & LQ-UQ & median & $\min -\max$ & LQ-UQ & \\
\hline Age [years] & 26 & $18-59$ & $21-48$ & 37 & $20-67$ & $29-56$ & 0.03 \\
\hline ALT U/L & 55 & 24-336 & $37-91$ & 52 & 23-201 & $39-77$ & $>0.01$ \\
\hline NFE2L2 & 2.42 & $9.21-12.32$ & $1.72-4.40$ & 2.01 & $0.22-6.03$ & $1.00-3.50$ & $>0.01$ \\
\hline GFER & 1.45 & $0.09-17.47$ & $0.97-2.57$ & 1.46 & $0.68-2.01$ & $0.05-2.55$ & $>0.01$ \\
\hline NQO1 & 0.89 & $0.02-17.47$ & $0.47-2.03$ & 0.58 & $0.38-1.62$ & $0.01-2.36$ & $>0.01$ \\
\hline
\end{tabular}

LQ - lower quartile; UP - upper quartile; ALT - alanine aminotranferase.

Table 3. Hepatic expression of GFER, NQO1 and NFE2L2 according to liver fibrosis

\begin{tabular}{|c|c|c|c|c|c|c|c|}
\hline & \multicolumn{3}{|c|}{$\begin{array}{c}\text { Staging }<2 \\
(n=8)\end{array}$} & \multicolumn{3}{|c|}{$\begin{array}{c}\text { Staging } \geq 2 \\
(n=34)\end{array}$} & \multirow{2}{*}{$p$-value } \\
\hline & median & $\min -\max$ & LQ-UQ & median & $\min -\max$ & LQ-UQ & \\
\hline Age [years] & 26 & $18-61$ & $20-33$ & 35 & $18-67$ & $26-50$ & $>0.01$ \\
\hline ALT U/L & 54.5 & $24-336$ & $42-83$ & 41.5 & $23-95$ & $25-79.5$ & $>0.01$ \\
\hline HCV viral load & 580,000 & $392,000-11,800,000$ & $2671,000-7,535,000$ & $3,040,000$ & $118,000-9,780,000$ & $381,000-6,390,000$ & $>0.01$ \\
\hline NFE2L2 & 3.96 & $0.21-12.32$ & $2.44-6.16$ & 2.05 & $0.22-7.76$ & $1.42-3.13$ & $=0.05$ \\
\hline GFER & 1.14 & $0.09-3.76$ & $0.35-1.82$ & 1.48 & $0.05-3.98$ & $1.04-2.14$ & $>0.01$ \\
\hline NQO1 & 0.79 & $0.24-9.32$ & $0.02-17.47$ & 0.77 & $0.01-5.48$ & $0.44-1.68$ & $>0.01$ \\
\hline
\end{tabular}

LQ - lower quartile; UP - upper quartile; ALT - alanine aminotranferase. 
Table 4. Hepatic expression of GFER, NQO1 and NFE2L2 according to liver inflammation

\begin{tabular}{|c|c|c|c|c|c|c|c|}
\hline & \multicolumn{3}{|c|}{$\begin{array}{c}\text { Grading }<2 \\
(n=30)\end{array}$} & \multicolumn{3}{|c|}{$\begin{array}{c}\text { Grading } \geq 2 \\
(n=12)\end{array}$} & \multirow[t]{2}{*}{$\mathrm{p}$-value } \\
\hline & median & $\min -\max$ & LQ-UQ & median & $\min -\max$ & LQ-UQ & \\
\hline Age [years] & 26 & $18-51$ & $20-33$ & 53 & 27-201 & $48.5-2.68$ & $<0.0001$ \\
\hline ALT U/L & 51 & $23-336$ & $35-73$ & 76 & $24-67$ & $53-108$ & $>0.01$ \\
\hline HCV viral load & $4,760,000$ & $118,000-11,800,000$ & $452,000-7,200,000$ & 809,000 & $221,000-9,780,000$ & $4,522,000-4,895,000$ & $>0.01$ \\
\hline GFER & 1.50 & $0.06-3.76$ & $0.97-2.14$ & 1.26 & $0.07-3.98$ & $0.89-1.96$ & $>0.01$ \\
\hline NQO1 & 0.79 & $0.01-17.24$ & $0.39-1.80$ & 0.76 & $0.05-3.66$ & $0.52-1.34$ & $>0.01$ \\
\hline NFE2L2 & 2.51 & $0.21-12.32$ & $1.72-4.40$ & 1.84 & $0.22-6.03$ & $1.13-2.68$ & $>0.01$ \\
\hline
\end{tabular}

LQ - lower quartile; UP - upper quartile; ALT - alanine aminotranferase.

Table 5. Hepatic expression of GFER, NQO1 and NFE2L2 according to the presence of liver steatosis

\begin{tabular}{|c|c|c|c|c|c|c|c|}
\hline & \multicolumn{3}{|c|}{$\begin{array}{l}\text { Without steatosis } \\
\qquad(n=30)\end{array}$} & \multicolumn{3}{|c|}{$\begin{array}{l}\text { With steatosis } \\
\qquad(\mathrm{n}=12)\end{array}$} & \multirow{2}{*}{$p$-value } \\
\hline & median & $\min -\max$ & LQ-UQ & median & $\min -\max$ & LQ-UQ & \\
\hline Age [years] & 27 & $18-67$ & $21-48$ & 38.5 & $18-59$ & $30-52.5$ & $>0.01$ \\
\hline ALT U/L & 52 & $23-201$ & $32-73$ & 76 & $39-336$ & $52-96$ & 0.03 \\
\hline HCV viral load & $4,370,000$ & $118,000-11,800,000$ & $392,000-6,390,000$ & $2,930,000$ & $221,000-8,750,000$ & $383,499.5-7,085,000$ & $>0.01$ \\
\hline GFER & 1.45 & $0.06-3.98$ & $0.90-1.96$ & 1.46 & $0.68-3.32$ & $1.15-2.30$ & $>0.01$ \\
\hline NQO1 & 0.76 & $0.03-17.47$ & $0.41-1.68$ & 0.87 & $0.01-3.17$ & $0.52-1.85$ & $>0.01$ \\
\hline NFE2L2 & 2.26 & $0.21-12.32$ & $1.75-4.16$ & 2.34 & $0.80-6.03$ & $1.46-3.21$ & $>0.01$ \\
\hline
\end{tabular}

LQ - lower quartile; UP - upper quartile; ALT - alanine aminotranferase.

Table 6. Correlations between hepatic expression of GFER, NQO1 and the NFE2L2 in patients with chronic HCV

\begin{tabular}{|l|c|c|c|c|}
\multirow{2}{*}{} & \multicolumn{2}{|c|}{ GFER } & \multicolumn{2}{c|}{ NQO1 } \\
\cline { 2 - 5 } & Spearman's rank correlation $\rho$ & $p$-value & Spearman's rank correlation $\rho$ & $p$-value \\
\hline NFELL2 & 0.22 & NS & 0.59 & $<0.0001$ \\
\hline
\end{tabular}

NS - not significant.

\section{Discussion}

Polymerase chain reaction proteins induce the production of more ROS in the liver than other hepatitis viruses. ${ }^{8-10}$ As excessive production of ROS can result in hepatocyte damage, an adequate antioxidant response is extremely important. The transcription factor $\mathrm{Nrf} 2$ plays a central role in stimulating the expression of various antioxidant-associated genes. Numerous reports describe that the antioxidant response is disturbed in subjects with HCV infection. ${ }^{11,12}$

It is possible that $\mathrm{HCV}$ can directly affect regulatory genes responsible for the antioxidant response, such as NFE2L2. Carvajal-Yepes et al. indicate that HCV prevents the entry of Nrf2 in the nucleus by the delocalization of sMaf proteins, thereby inhibiting the induction of Nrf2/AREregulated genes. ${ }^{13}$ Reduced levels of glutathione and other antioxidants have been reported in liver biopsies in chronic $\mathrm{HCV}{ }^{14,15}$ Interestingly, these results correspond to those of an in vitro study conducted by Wen at al., which indicates the decreased induction of HMOX-1 in hepatocyte cell lines expressing the $\mathrm{HCV}$ core protein in response to oxidative stress. ${ }^{12}$ Conversely, Inanov et al. demonstrated that $\mathrm{HCV}$ proteins activate the Nrf2/ARE pathway in HCVcc infected Huh7.5 cells and induce the transcription of antioxidant genes. ${ }^{9}$ Our results confirm the involvement of Nrf2 in the regulation of the antioxidant defense system, in that a positive correlation was observed between NFE2L2 and NQO1 expression.

Interestingly, the literature presents several contradicting opinions on the role of antioxidant enzymes in HCV replication. Zhu et al. demonstrated that heme oxygenase-1 overexpression is associated with decreased HCV replication in vitro. ${ }^{16}$ In contrast, Ghaziani et al. found the heme oxygenase- 1 gene to be upregulated in Huh-7 cells expressing $\mathrm{HCV}$ proteins. ${ }^{17}$ It is still not clear whether antioxidant enzymes directly affect HCV replication in vivo; however, our present findings indicate that the hepatic expression of GFER, NQO1 and NFE2L2 was not related to $\mathrm{HCV}$ viremia.

A number of studies have examined the role of the antioxidant response in hepatocyte injury. ${ }^{18,19}$ In a study 
conducted by Kumar et al., the decreased hepatic expression of ALR was found in alcohol-induced fibrosis in mice model. ${ }^{19}$ Conversely, Cheng et al. reported the expression of NQO1 to be increased in alcoholic cirrhosis. ${ }^{20}$

Our present findings did not indicate any association between hepatic expression of GFER and NQO1 with the progression of liver inflammation and fibrosis in chronic $\mathrm{HCV}$. However, higher hepatic expression of NFE2L2 was observed in patients with a lower stage of fibrosis.

Interestingly, Nrf2 activation directly inhibits the functioning of TGF- $\beta 1$ (transforming growth factor- $\beta 1$ ) and subsequently suppresses the collagen-producing hepatic stellate cells in a liver fibrosis mouse model. ${ }^{21}$ These findings are in accordance with Jiang et al., who reported stronger Nrf2 staining in HCV infected Huh 7.5.1 hepatocytes and in liver biopsy specimens obtained from chronic $\mathrm{HCV}$ patients with a low grade of inflammation and fibrosis. ${ }^{22}$

Moreover, experimental studies show that the decreased expression of ALR and Nfr2 can result in liver steatosis by lowering the activity of several enzymes important for fatty acid $\beta$-oxidation and the promoting factors that regulate adipocyte differentiation and lipogenesis. ${ }^{19,23,24}$

However, our findings do not confirm the influence of NFE2L2 and GFER on the presence of liver steatosis in HCV infection in vivo. The pathogenesis of liver steatosis in HCV infection is complex. Not only the host but also viral mechanisms likely contribute to the development of hepatic steatosis in HCV infection. ${ }^{25,26}$

The limitation of this study is the lack of the assessment of oxidative stress markers in the liver. Therefore, further studies are needed to precisely clarify the simultaneous role of the oxidative stress and antioxidant response in pathogenesis of chronic HCV. In conclusion, the hepatic expression of NFE2L2 is associated with NQO1 and low stage of fibrosis in patients infected with HCV. However, the study subgroup with mild fibrosis was limited to 8 patients.

\section{ORCID iDs}

Kamila Małgorzata Wójcik (1) https://orcid.org/0000-0003-2465-401X Anna Piekarska (1) https://orcid.org/0000-0002-7188-4881

Bożena Szymańska (1) https://orcid.org/0000-0002-0775-7570

Elżbieta Jabłonowska (1) https://orcid.org/0000-0002-7282-1225

\section{References}

1. Chen SL, Morgan TR. The natural history of hepatitis $\mathrm{C}$ virus (HCV) infection. Int J Med Sci. 2006;3(2):47-52.

2. Lauer GM, Walker BD. Hepatitis C virus infection. N Eng/ J Med. 2001; 345(1):41-52.

3. Tanikawa K, Torimura T. Studies on oxidative stress in liver diseases: Important future trends in liver research. Med Mol Morphol. 2006; 39(1):22-27.

4. Clement S, Pascarella S, Negro F. Hepatitis C virus infection: Molecular pathways to steatosis, insulin resistance and oxidative stress. Viruses. 2009;1(2):126-143.
5. Okuda M, Li K, Beard MR, et al. Mitochondrial injury, oxidative stress, and antioxidant gene expression are induced by hepatitis $C$ virus core protein. Gastroenterology. 2002;122(2):366-375.

6. Zhu H, Li Y. NAD(P)H: Quinone oxidoreductase 1 and its potential protective role in cardiovascular diseases and related conditions. Cardiovasc Toxicol. 2012;12(1):39-45.

7. Francavilla A, Hagiya M, Porter KA, Polimeno L, Ihara I, Starzl TE. Augmenter of liver regeneration: Its place in the universe of hepatic growth factors. Hepatology. 1994;20(3):747-757.

8. Mitochondrially associated hepatitis $B$ virus $X$ protein constitutively activates transcription factors STAT-3 and NF-kappa B via oxidative stress. Mol Cell Biol. 2001;21(22):7721-7730.

9. Masalova OV, Kochetkov SN, Isaguliants MG. Hepatitis C virus proteins activate NRF2/ARE pathway by distinct ROS-dependent and independent mechanisms in HUH7 cells. PLoS One. 2011;6(9):249-257.

10. Farinati F, Cardin R, De Maria N, et al. Iron storage, lipid peroxidation and glutathione turnover in chronic anti-HCV positive hepatitis. J Hepatol. 1995;22(4):449-456.

11. Qadri I, Iwahashi M, Capasso JM, et al. Induced oxidative stress and activated expression of manganese superoxide dismutase during hepatitis C virus replication: Role of JNK, p38 MAPK and AP-1. Biochem J. 2004;15(3):919-928.

12. Wen F, Brown KE, Britigan BE, Schmidt WN. Hepatitis C core protein inhibits induction of heme oxygenase- 1 and sensitizes hepatocytes to cytotoxicity. Cell Biol Toxicol. 2008;24(2):175-188.

13. Carvajal-Yepes M, Himmelsbach K, Schaedler S, et al. Hepatitis C virus impairs the induction of cytoprotective Nrf2 target genes by delocalization of small Maf proteins. J Biol Chem. 2011;18(286):8941-8951.

14. Swietek K, Juszczyk J. Reduced glutathione concentration in erythrocytes of patients with acute and chronic viral hepatitis. J Viral Hepat. 1997;4(2):139-141.

15. Venturini D, Simao AN, Barbosa DS, et al. Increased oxidative stress, decreased total antioxidant capacity, and iron overload in untreated patients with chronic hepatitis C. Dig Dis Sci. 2010;55(4):1120-1127.

16. Zhu Z, Wilson AT, Mathahs MM, et al. Heme oxygenase-1 suppresses hepatitis $C$ virus replication and increases resistance of hepatocytes to oxidant injury. Hepatology. 2008;48(5):1430-1439.

17. Ghaziani T, Shan Y, Lambrecht RW, et al. HCV proteins increase expression of heme oxygenase-1 (HO-1) and decrease expression of Bach1 in human hepatoma cells. J Hepatol. 2006;45(1):5-12.

18. Sass G, Soares MC, Yamashita K, et al. Heme oxygenase-1 and its reaction product, carbon monoxide, prevent inflammation-related apoptotic liver damage in mice. Hepatology. 2003;38(4):909-918.

19. Kumar S, Wang J, Rani R, Gandhi CR. Hepatic deficiency of augmenter of liver regeneration exacerbates alcohol-induced liver injury and promotes fibrosis in mice. PLoS One. 2016;25(1):e0147864.

20. Cheng ML, Lu YF, Chen H, Shen ZY, Liu J. Liver expression of Nrf2related genes in different liver diseases. Hepatobiliary Pancreat Dis Int. 2015;14(5):485-491.

21. Choi HK, Pokharel YR, Lim SC, et al. Inhibition of liver fibrosis by solubilized coenzyme Q10: Role of Nrf2 activation in inhibiting transforming growth factor-beta1 expression. Toxicol Appl Pharmacol. 2009;240(3):377-384.

22. Jiang $Y, B a o H, G e Y$, et al. Therapeutic targeting of GSK3 $\beta$ enhances the Nrf2 antioxidant response and confers hepatic cytoprotection in hepatitis C. Gut. 2015;64(1):168-179.

23. Tanaka Y, Aleksunes LM, Yeager RL, et al. NF-E2-related factor 2 inhibits lipid accumulation and oxidative stress in mice fed a high-fat diet. J Pharmacol Exp Ther. 2008;325(2):655-664.

24. Madison BB. Srebp2: A master regulator of sterol and fatty acid synthesis. J Lipid Res. 2016;57(3):333-335.

25. Hayes JD, Dinkova-Kostova AT. The Nrf2 regulatory network provides an interface between redox and intermediary metabolism. Trends Biochem Sci. 2014;39(4):199-218.

26. Perlemuter G, Sabile A, Letteron $P$, et al. Hepatitis $C$ virus core protein inhibits microsomal triglyceride transfer protein activity and very low density lipoprotein secretion: A model of viral-related steatosis. FASEB J. 2002;16(2):185-194. 